\title{
Online Integrative Teaching Strategies: Thematic and Focus Inquiry for Improved Science Process Skills
}

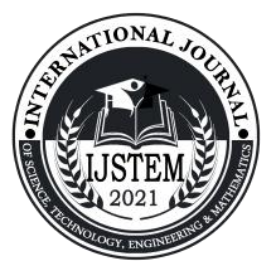

\author{
${ }^{1}$ Angelo R. Reyes \& ${ }^{2}$ John Vincent C. Aliazas
}

\begin{abstract}
The education system has recently been shattered by an unprecedented health crisis, which has affected its very foundation and caused it to collapse. Likewise, education is the only industry that has completely transitioned to an online modality in most countries, and it is the only one that has done so thoroughly. The current condition necessitates further investigation into students' online learning experiences, which may be the most beneficial alternative for continuing education experiences throughout the COVID-19 pandemic. This study sought to determine the effectiveness of two online integrative teaching strategies (focusing inquiry teaching strategy and the thematic teaching strategy) on students' integrated science process skills (interpreting data, defining, hypothesizing and experimenting skills). An experimental research design included two integrative sections, containing thirty (30) students each, taking up Earth and Life Science subjects from Santisimo Rosario Integrated High School. The first section was exposed to the thematic teaching strategy while the second to the focusing inquiry teaching strategy. The integrated science process skills of the learners were measured through a validated researcher-made assessment tool. The findings revealed that there had been an improvement in the integrated science process skills of the students after being exposed to OITS. Likewise, significant differences exist in the respondents' pretest and post-test scores exposed to OITS (focusing inquiry teaching strategy and thematic teaching strategy). Furthermore, ISPS among the two groups show no significant differences in the post-test scores. The findings of this study may aid in the development of a modified programs that is more appropriate for students who are adjusting to the new normal.
\end{abstract}

Keywords:

integrative teaching strategies, integrated science process skills, online learning, focusing inquiry teaching strategy, thematic teaching strategy

Suggested Citation: Reyes, A.R. \& Aliazas J.C. (2021). Online Integrative Teaching Strategies: Thematic and Focus Inquiry for Improved Science Process Skills. International Journal of Science, Technology, Engineering and Mathematics, Volume 1, Issue 2, pp. 19- 38.

\footnotetext{
About the authors:

${ }^{1}$ Corresponding author. Pre-Service Teacher, Laguna State Polytechnic University, San Pablo City, Laguna, Philippines

${ }^{2}$ Assistant Professor 1, Laguna State Polytechnic University, San Pablo City, Laguna, Philippines
} 


\section{Introduction}

Most students during the pandemic faced numerous challenges on the online learning using various online modalities such as Google Classroom, Google Meet, Zoom, and other educational platforms. The primary problem is the struggles of every student to adapt to the changing environment and the acquisition of learning (Arinto, 2016). Most learners deal with different approaches and strategies to adapt to the new mode of studying and learning (Shahali \& Halim, 2011). Technical issues may also arise, especially for the students with a lack of financial resources to afford gadgets and skills to operate the applications and modes used by teachers and professors in the new learning environment (Desyandri et Al., 2019). Computer literacy has also become one of the problems nowadays. Due to the face-to-face learning environment, which only relies on textbooks and other printed learning materials, the students need to adjust and be computer literate to acquire information and lessons using different technological media (Fu, 2013). Computer literacy became one of the most needed skills in pursuing online learning. Next is the time management issue, changing the physical learning environment from the four corners of the classroom to the room of every home. Time management became one of these barriers that the students face (Panoy, 2017; Baharom et Al., 2020). Every individual has their duties and responsibilities at home. Some of them doubled due to the occurrence of quarantine. It is undeniable that managing time for commitments and chores at home competes with the time that must be allotted for studying (Haug \& Ødegaard, 2014). It is a burden for every student to carry out their activities, performance tasks, and assignments when their chores are needed to accomplish first (Shahali \& Halim, 2011). And last is self-motivation; this pandemic brought many casualties and problems to everyone, ruining individual physical health and draining mental health (Vanoostveen, Desjardins, \& Bullock, 2019). The government agencies are doing everything they can to help push the levels and standards of education, upbringing the knowledge and information needed by the students during a crisis (Aliazas et al., 2021). Putting their mind in education, as they faced this problem brought by the crisis causes their mental health to be considered, and gaining self-motivation is their primary concern. Pushing their boundaries to achieve and finish their course requirements. 
From these five problems, the researchers focus on home-based learning does not provide reminders to students about their lessons, activities, and assignments, unlike in the regular school setup (Baharon et Al., 2020). Resulting in the students developing lazy behavior and becoming forgetful eventually, especially towards the science subject. In a recent article published by neurobiologists Blake Richards and Paul Frankland (2017), they question the widely held belief that forgetting is a process of loss, in which vital information is gradually washed away despite our best efforts to keep it. The researchers state that forgetting is natural and inevitable to everyone despite the best efforts of an individual to remember it. Memory's purpose is to accurately retain facts and optimize decision-making in a complex, rapidly changing environment (Panoy, 2017; Richards \& Frankland, 2017). Even yet, it's worth noting that the human mind only retains a portion of the information it seeks, reads, or hears. These little bits of data will be used and taken into account when making decisions and making judgments (Ortiz \& Aliazas, 2021).

According to CNS West's research, the human brain can hold the equivalent of 2.5 million terabytes of digital memory, including memories, experiences, knowledge, and other data processed by the brain. It proves that the student's ability usually falls on short-term memory knowledge needed for the current academic year (Hanfstingl, Benke, \& Zhang, 2019). Lessons and lectures from the previous academic year were forgotten and did not integrate into learning new topics in the current year (Panoy, 2017). This resulted in the students' poor academic performance in science. It became a burden for every student as the curriculum provides a spiral way of introducing the science subject topics to understand better (Lati, Saksri, \& Promarak, 2012). As a result, it is necessary to establish whether or not online integrative teaching strategies will effectively improve students' integrated science process skills.

\section{Literature review}

\subsection{Thematic Teaching}

The process of selecting and highlighting a theme in an instructional unit, module, course, or series of classes is known as thematic teaching (Desyandri et Al., 2019). It's often interdisciplinary, emphasizing the link between academic subjects and everyday life (Utami 
\& Mustadi, 2019). Themes can be in the form of issues or general questions. Thematic learning is intimately linked to interdisciplinary or integrated instruction, subject, project, or phenomenon-based learning (Resor, 2017). Although this technique is equally applicable in secondary schools and adult learners, thematic teaching is frequently associated with teambased approaches in elementary and intermediate schools (Vanoostveen, Desjardins, \& Bullock, 2019). The method is more commonly known as theme-based instruction in teaching a second or foreign language (McCarty, 2005). According to thematic education, students learn best to connect new information across the curriculum to their own lives, experiences, and communities.

According to cognitive learning theory, we process information when we learn (Hanfstingl, Benke, \& Zhang, 2019). It implies that the learner is an active participant in the process, bringing their skills, knowledge, memories, and pertinent information from previous experiences to the table. It also underlines the importance of internal and exterior thoughts in the cognitive process (Hanfstingl, Benke, \& Zhang, 2019). Students' mental capacity to acquire and retain information will be boosted by integrating the focused inquiry teaching technique and thematic teaching in science topics, adjusting it to what they already know for more significant learning and retention for a more extended period (Desyandri et Al., 2019; Fatmawati \& Rustaman, 2020). This strategy focuses primarily on the students' progress and assists the teacher in effectively teaching the subject (Shahali\& Halim, 2011). Internal and external factors impact a person's mental processes, which can help them learn more effectively (Hanfstingl, Benke, \& Zhang, 2019). Learning delays and challenges emerge when attention, observation, retrieval from long-term memory, and categorization are used as cognitive techniques (McCarty, 2005; Panoy, 2017; Fitriana et Al., 2020).

\subsection{Focusing Inquiry Teaching}

The development and practice of critical thinking and problem-solving abilities are the primary goals of inquiry-based teaching. Problem-based learning (Dostál \& Gregar, 2015) is a type of inquiry-based learning commonly used in small-scale inquiries, projects, and research. A facilitator rather than a lecturer frequently supports Inquiry-based learning (Panoy, 2017; Baharon et Al., 2020). Inquirers will find and research topics and questions to produce information or solutions (Lati, Saksri, \& Promarak, 2012). Inquiry-based learning is 
the foundation of constructivist learning theories. According to the constructivism learning theory, students construct their learning based on prior experiences (Beaumont \& Soyibo, 2010). Students combine what they have learned with their prior knowledge and experiences to create a unique world. The integration process is used to transfer knowledge and information in this learning approach, emphasizing learning as a personal and unique process for each student (Utami \& Mustadi, 2019).

Students' prior experiences are used in the focusing inquiry teaching strategy to acquire new information, which is then added to their stack knowledge (Lati, Saksri, \& Promarak, 2012). On the other hand, thematic teaching employs students to integrate the learning process (McCarty, 2005; Desyandri et Al., 2019). The learner-centered integration approach was made easier by dealing with real-life applications of knowledge and information (Fitriana et Al., 2020).

Constructivism's central tenet is that human learning is created, and learners build new knowledge on top of their previous education. This prior knowledge influences new learning opportunities' unique or modified ability (Lati, Saksri, \& Promarak, 2012). Learners are viewed as an 'empty vessel' filled with wisdom, ideas, thoughts, and information in the passive view of teaching (Panoy, 2017; Fitriana et Al., 2020). According to constructivism, they can only construct meaning through active engagement with the world, such as realworld problem-solving experiments. Educators use this theory to transfer their knowledge to their students effectively, so it is so important.

\subsection{Connectivism Theory}

The connectivism theory is inherently a future-focused learning theory, with a pedagogical perspective that considers the changing nature of knowledge acquisition in the digital age. George Siemens developed it as a type of learning theory. It is based on what the children are expected to know and focuses on learning at a specific time. This theory enables students to locate and acquire knowledge by considering the learners' existing schemas (Fitriana et Al., 2020). They are assisted in processing and threading various strands of ideas, information, and comprehension (Saat, 2010; Aliazas et al., 2021). It's a lesson that explains how internet technologies have given students new ways to learn information effectively and 
efficiently. It emphasizes that a great deal of knowledge can be gained through connections and other means (Desyandri et Al., 2019). It can be viewed as a global strategy or educational theory (Shahali \& Halim, 2011). Acquiring information trends begins to move learning theories into other forms by including technology and connection making as learning (Baharon et Al., 2020).

\section{Methodology}

This study employed an experimental research design. In education, experimental research design refers to developing a set of techniques to evaluate a hypothesis (Resor, 2017; Ortiz \& Aliazas, 2021). It's the study that takes a scientific method and involves two groups of variables (Huong et al., 2018). The first set serves as a baseline against which you can compare the differences in the second set.

This study focused on using two online integrative teaching strategies and their effects on the integrated science process skills of Santisimo Rosario Integrated Highschool students regarding the teaching of Science 12 subjects. The first set of variables to be used are the two online integrative teaching strategies, and the second set to be measured is the students' integrated science process skills. The two online integrative teaching strategies, namely: (1) Focusing Inquiry teaching strategy and; (2) Thematic teaching strategy, will utilize by the researcher to identify its effects on the integrated science process skills of students in terms of interpreting data, defining, hypothesizing and experimenting (Utami \& Mustadi, 2019). The researcher will use this type of research to utilize the two online integrative teaching strategies and their effects on developing their integrated science process skills (Saat, 2010).

Respondents for this research will be students from two heterogeneously grouped classes from Grade 12, with 30 students in each section in Santisimo Rosario Integrated High School during 2020-2021. Concerning the school records, the researchers will ensure that the chosen section will qualify the following conditions: 1) the two sections will be Grade 12 students enrolled at Santisimo Rosario Integrated Highschool for the academic year 20202021; 2) taking up the exact Science 12 subjects, and 3) they will be under the supervision of 
the same teacher throughout the implementation of two online integrative teaching strategies. The study instruments will include two sets of lesson plans and the pretest and post-test to measure the students' integrated science process skills.

The researcher prepared a pre and post-test that includes the Integrated Science Process Skills Test validated by master teacher/s and head teacher/s, and an English teacher for the language structure. Furthermore, the researcher drafted the lesson plan to execute the two online integrative teaching strategies (Shahali \& Halim, 2011; Utami \& Mustadi, 2019).

The researcher prepared a pre and post-test that includes the Integrated Science Process Skills Tests validated by master teacher/s and head teacher/s. A semi-detailed lesson plan is to be used in the experimental research. After the instrument's validation to be used, permission to conduct the research was secured from the different offices involved in the conduct of the study. With Santisimo Rosario Integrated Highschool as the target school, a letter addressed to the school head was sent as a formal request. Two groups of Grade 12 students were taught utilizing two online integrative teaching strategies: a focusing-inquiry method for the first segment and a thematic teaching strategy for the second.

This study employed both descriptive and inferential statistics to give meaning to the set of data gathered (Panoy, 2017). In response to the presentation of the descriptive data on the pretest and post-test scores of the student-respondents on the integrated science process skills test, frequency and percentages are to be used (Saat, 2010; Utami \& Mustadi, 2019). To analyze the data's result to be gathered in response to the inferential question of pretest and post-test comparison within groups, paired t-test will be used (Ortiz \& Aliazas, 2021). The t-test for independent samples will be used to determine whether there is a significant difference in the performance of the post-test score of the two groups of respondents exposed to two different inquiry-based teaching styles. 


\section{Findings and Discussion}

Table 1

Pretest and post-test performance of the respondents in terms of defining

\begin{tabular}{cccccccccc}
\hline & \multicolumn{3}{c}{ Thematic Teaching } & \multicolumn{3}{c}{ Focusing Inquiry Teaching } & & \\
\cline { 2 - 7 } Score & \multicolumn{2}{c}{ Pretest } & \multicolumn{2}{c}{ Posttest } & \multicolumn{2}{c}{ Pretest } & \multicolumn{2}{c}{ Posttest } & Interpretation \\
\cline { 2 - 7 } & F & $\%$ & F & $\%$ & F & $\%$ & F & $\%$ & \\
\hline $9-10$ & 1 & 3.3 & 6 & 20.0 & 1 & 3.3 & 6 & 20.0 & Outstanding \\
$7-8$ & 8 & 26.7 & 21 & 70.0 & 5 & 16.7 & 20 & 66.7 & Proficient \\
$5-6$ & 13 & 43.3 & 3 & 10.0 & 15 & 50.0 & 4 & 13.3 & Approaching \\
$3-4$ & 8 & 26.7 & - & - & 9 & 30.0 & - & - & Proficiency \\
$0-2$ & - & - & - & - & - & - & - & - & Beveloping \\
\hline Total & 30 & 100.0 & 30 & 100.0 & 30 & 100.0 & 30 & 100.0 & \\
\hline
\end{tabular}

The table shows the performance of the Grade 12 students in the pretest and post-test in terms of integrated science process skills of defining. This part of the test is composed of 10-item multiple-choice that will measure the student's defining skills. The first group that will undergo the Thematic teaching strategy shows that $43.3 \%$ of the pretest scores fall under the Approaching Proficiency, and only 3.3\% got the Outstanding score. However, upon integrating the thematic teaching strategy. Before implementing the integrative teaching strategy, 13 students have average defining skills, and only 1 out of 30 respondents have outstanding defining skills. The post-test of this group shows that $70 \%$ of the class became Proficient, and the Outstanding student's percentage rose to $20 \%$. This means that 21 out of 30 became proficient in their defining skills, and six students scored 9-10 and displayed outstanding ability in their defining skills.

The second group that will undergo a Focusing inquiry teaching strategy shows that $50 \%$ of their scores fall under the Approaching Proficiency, and 3.3\% reach the Outstanding score. It emphasizes that half of the class has an average defining skill, and 1 out of 30 students got an outstanding score in defining before applying the teaching strategy. However, upon administering the Focusing inquiry teaching strategy, their post-test reveals that $66.7 \%$ or 20 of the class developed their defining skills and raised them to Proficient levels. In comparison, $20 \%$ of the integrative group or six students reach their outstanding defining level through the focusing inquiry teaching strategy. This increased student's performance in defining skills implied that the learners could describe the variables and subject presented in 
the topic (Fatmawati \& Rustaman, 2020). They can tell the physical attributes of the eight planets in the solar system and their internal characteristics (Panoy, 2017; Ortiz \& Aliazas, 2021). It also explained that the learners could remember and retain the most notable and unique features among the planets mentioned.

Table 2

Pretest and post-test performance of the respondents in terms of hypothesizing

\begin{tabular}{cccccccccc}
\hline & \multicolumn{3}{c}{ Thematic Teaching } & \multicolumn{3}{c}{ Focusing Inquiry Teaching } & & \\
\cline { 2 - 7 } Score & \multicolumn{2}{c}{ Pretest } & \multicolumn{2}{c}{ Posttest } & \multicolumn{2}{c}{ Pretest } & \multicolumn{2}{c}{ Posttest } & Interpretation \\
\cline { 2 - 7 } & F & $\%$ & F & $\%$ & F & $\%$ & F & $\%$ & \\
\hline 5 & - & - & - & - & - & - & - & - & Outstanding \\
4 & - & - & - & - & - & - & - & - & Proficient \\
3 & - & - & 7 & 23.3 & 1 & 3.3 & 5 & 16.7 & Approaching \\
2 & 17 & 56.7 & 23 & 76.7 & 13 & 43.3 & 25 & 83.3 & Proficiency \\
1 & 13 & 43.3 & - & - & 16 & 53.3 & - & - & Beveloping \\
\hline Total & 30 & 100.0 & 30 & 100.0 & 30 & 100.0 & 30 & 100.0 & \\
\hline
\end{tabular}

The table above shows the pretest and post-test performance of the Grade 12 student's hypothesizing skills. This part of the test is composed of 2 questions, wherein the students will conclude and hypothesize what will happen if the scenario given were about to happen. The students were task to explain in just 2 to 3 sentences and will be scored accordingly. The first group that will undergo the Thematic teaching strategy displays $56.7 \%$ of their pretest score under the Developing level, and $43.3 \%$ achieved Beginning in their hypothesizing skills. This explains that 17 out of 30 respondents developed, and 13 were beginning in hypothesizing ability skills. However, after integrating the Thematic teaching Strategy, the student's post-test shows that learners under developing increase to $76.7 \%$ or 23 learners of the class and $23.3 \%$ or 7 of them reached Approaching Proficiency, which tells that the learners were hypothesizing skills increases.

The second group that will take the Focusing inquiry teaching exhibit $53.3 \%$ of pretest results under Beginning level, and just 3.3\% scored 3 for Approaching Proficiency level. This indicates that 16 out of 30 respondents are beginning their hypothesizing skills, and only one student is approaching proficiency. However, after the utilization of the Focusing inquiry teaching strategy, the data of their post-test reveals that $83.3 \%$ of the class or 25 students reached the developing level and 16.7\%, which are five students who achieved 
Approaching Proficiency in terms of their hypothesizing skills after being exposed to the teaching strategy. The student's integrated science process skills in terms of hypothesizing are developed. The findings showed that the learners could understand their situation and draw their hypothesis about it. In terms of the scenario, they can formulate and state their expected results and outcomes if creating the Solar System never takes place in the first place. They may also explain why Earth has unique and distinguishing properties that support life among the Solar System's planets. Their ability to formulate hypotheses and forecast findings and outcomes was honed and improved.

\section{Table 3}

Pretest and post-test performance of the respondents in terms of experimenting

\begin{tabular}{|c|c|c|c|c|c|c|c|c|c|}
\hline \multirow{3}{*}{ Score } & \multicolumn{4}{|c|}{ Thematic Teaching } & \multicolumn{4}{|c|}{ Focusing Inquiry Teaching } & \multirow{3}{*}{ Interpretation } \\
\hline & \multicolumn{2}{|c|}{ Pretest } & \multicolumn{2}{|c|}{ Posttest } & \multicolumn{2}{|c|}{ Pretest } & \multicolumn{2}{|c|}{ Posttest } & \\
\hline & $\mathrm{F}$ & $\%$ & $\mathrm{~F}$ & $\%$ & $\mathrm{~F}$ & $\%$ & $\mathrm{~F}$ & $\%$ & \\
\hline $13-15$ & 13 & 43.3 & 30 & 100.0 & 13 & 43.3 & 30 & 100.0 & Outstanding \\
\hline $10-12$ & 8 & 26.7 & - & - & 8 & 26.7 & - & - & Proficient \\
\hline $7-9$ & 5 & 16.7 & - & - & 5 & 16.7 & - & - & $\begin{array}{l}\text { Approaching } \\
\text { Proficiency }\end{array}$ \\
\hline $4-6$ & 4 & 13.3 & - & - & 4 & 13.3 & - & - & Developing \\
\hline $0-3$ & - & - & - & - & - & - & - & - & Beginning \\
\hline Total & 30 & 100.0 & 30 & 100.0 & 30 & 100.0 & 30 & 100.0 & \\
\hline
\end{tabular}

Table 3 shows the performance of Grade 12 students in their experimenting skills. This part of the test contains a 15-item true or false quiz, wherein the learners will classify each statement if it is factual or not. Each item will have two ideas that respondents will analyze if it is true or false, and after that, they will choose the letter corresponding to the result of the two statements. This part will measure the student's experimenting skills by analyzing and validating each information presented in the test. The pretest of the first and second groups that will take the integrative teaching strategy display $43.3 \%$ of them scored from 13 to 15 and is considered Outstanding. This means that the students from both groups have outstanding experimenting skills even before utilizing the online integrative teaching strategy.

The data above of their post-test result shows that the student's scores range from 13 to 15 and that both classes' experimenting skills were outstanding. However, these results were maximized after the online integrative teaching strategies were utilized. The findings 
revealed that the learner's integrated science process skills in terms of their experimenting skills are exceptional. The students can demonstrate their dept knowledge and skills in experimentation by analyzing and evaluating appropriate questions presented (Saat, 2010; Panoy, 2017; Ortiz \& Aliazas 2021). Through their experimenting skills, they can describe and identify if the given statements were presenting facts or not.

\section{Table 4}

Pretest and post-test performance of the respondents in terms of interpreting data

\begin{tabular}{cccccccccc}
\hline & \multicolumn{3}{c}{ Thematic Teaching } & \multicolumn{3}{c}{ Focusing Inquiry Teaching } & & \\
\cline { 2 - 7 } Score & \multicolumn{2}{c}{ Pretest } & \multicolumn{2}{c}{ Posttest } & \multicolumn{2}{c}{ Pretest } & \multicolumn{2}{c}{ Posttest } & Interpretation \\
\cline { 2 - 7 } & F & $\%$ & F & $\%$ & F & $\%$ & F & $\%$ & \\
\hline $9-10$ & 1 & 3.3 & 8 & 26.7 & - & - & 8 & 26.7 & Outstanding \\
$7-8$ & 1 & 3.3 & 19 & 63.3 & 3 & 10.0 & 20 & 66.7 & Proficient \\
$5-6$ & 16 & 53.3 & 3 & 10.0 & 17 & 56.7 & 2 & 6.7 & Approaching \\
$3-4$ & 12 & 40.0 & - & - & 10 & 33.3 & - & - & Proficiency \\
$0-2$ & - & - & - & - & - & - & - & - & Beveloping \\
\hline Total & 30 & 100.0 & 30 & 100.0 & 30 & 100.0 & 30 & 100.0 & \\
\hline
\end{tabular}

This component of the test consisted of a 10-item explanatory assessment in which students have presented a diagram depicting the evolution of the Solar System. Their task is to explain the formation of the system by utilizing the table shown above. The table indicates the performance of the Grade 12 students in terms of their interpreting data skills. They will be scored accordingly based on the rubrics.

The group that will undergo the Thematic teaching strategy shows that $54.3 \%$ of learners belong to the Approaching Proficiency level and 3.3\% for both Proficient and Outstanding level. This explains that most students from the first group, 16 out of 30, have an approaching proficiency level in terms of interpreting data skills and 1 for both proficiency and outstanding level. After implementing the Thematic Teaching strategy, the post-test of the first group shows a $63.3 \%$ increase in their class Proficiency level, and $26.7 \%$ of them scored under Outstanding level. This indicates that 19 out of 30 respondents became proficient, and 8 achieved outstanding interpreting data skills.

This study implies that the pretest scores of both groups reveal that they have an outstanding level of integrated science process skills in terms of their experimenting skills. However, both groups exhibit a beginning to developing level in terms of their skills in 
formulating hypotheses. After utilizing the designated integrative teaching strategies, the post-test results indicate that both groups still have outstanding experimenting skills (Ortiz \& Aliazas, 2021). This part of the test has the highest number of items that help them analyze the statements effectively. It is then followed by approaching proficiency level of defining and interpreting data skills (Panoy, 2017). It is then followed by defining and interpreting data that can be construed as under proficiency level (Beaumont \& Soyibo, 2010). The students exhibit their mastery and retention in remembering the meaning of terminologies used in the module and interpreting and explaining it independently (McCarty, 2005). The minor skill that is enhanced to the students of both groups is their hypothesizing skill (Fitriana et Al., 2020). Both groups can reach the developing to approaching proficiency level of skills, and none of the group falls under the beginning level.

The findings revealed that the learner's interpreting data skills are developed to become Proficient. The data shows that the interpreting data of the students were enhanced and that they can identify the subjects of the topic they are taught. The respondents were lectured and discussed creating the Solar system, including the heavenly bodies present inside it. After that, the test was given to state and narrated how the system was formed based on their understanding. The learners can remember and organize the things they understand step-by-step to state the process correctly (McCarty, 2005). They can absorb the concepts and techniques included in the Solar system formation and explain it using their own words, relying only on what they understand and remember from the lesson taught.

The study conducted by Beaumont \& Soyibo (2010) utilized and developed an integrated science process skills test to collect data. In this light, the researchers also make a 40-item test to measure the student's Integrated Science Process Skills in defining, hypothesizing, experimenting, and interpreting data skills. The subjects' mean score of the following integrated science process skills and their performance are listed in decreasing order: interpreting data, experimenting, and defining and formulating hypotheses (McCarty, 2005; Saat, 2010). However, this study implies that the mean scores of the two integrative groups indicate their performance in the integrated science process skills listed in decreasing order being: experimenting, interpreting data, defining, and hypothesizing (Beaumont \& Soyibo, 2010). The result reveals that the students performed better in their experimenting skills because they can analyze and evaluate each statement given in the test accordingly. 
Table 5

Test of difference between the pretest scores performance of the two groups of respondents on integrated science process skills.

\begin{tabular}{|c|c|c|c|c|c|c|c|c|}
\hline \multirow{3}{*}{ Skills } & \multirow{3}{*}{ Group } & \multirow{3}{*}{ Mean } & \multirow{3}{*}{$\mathrm{SD}$} & \multicolumn{5}{|c|}{ t-test for Equality of Means } \\
\hline & & & & \multirow[t]{2}{*}{$\mathrm{T}$} & \multirow[t]{2}{*}{ Sig. } & \multirow{2}{*}{$\begin{array}{l}\text { Mean } \\
\text { Diff. }\end{array}$} & \multicolumn{2}{|c|}{$\begin{array}{l}95 \% \mathrm{Cl} \text { of the } \\
\text { Diff. }\end{array}$} \\
\hline & & & & & & & Lower & Upper \\
\hline \multirow{2}{*}{ Defining } & TT & 5.70 & 1.60 & \multirow{2}{*}{.489} & \multirow{2}{*}{.627} & \multirow{2}{*}{.200} & \multirow{2}{*}{-.619} & \multirow{2}{*}{1.019} \\
\hline & FIT & 5.50 & 1.57 & & & & & \\
\hline \multirow{2}{*}{ Hypothesizing } & $\mathrm{TT}$ & 2.50 & 0.86 & \multirow{2}{*}{.141} & \multirow{2}{*}{.889} & \multirow{2}{*}{.033} & \multirow{2}{*}{-.442} & \multirow{2}{*}{.508} \\
\hline & FIT & 2.47 & 0.97 & & & & & \\
\hline \multirow{2}{*}{ Experimenting } & TT & 8.03 & 3.22 & \multirow{2}{*}{.340} & \multirow{2}{*}{.735} & \multirow{2}{*}{.267} & \multirow{2}{*}{-1.305} & \multirow{2}{*}{1.838} \\
\hline & FIT & 7.77 & 2.85 & & & & & \\
\hline \multirow{2}{*}{ Interpreting Data } & TT & 4.90 & 1.42 & \multirow{2}{*}{-.294} & \multirow{2}{*}{.770} & \multirow{2}{*}{-.100} & \multirow{2}{*}{-.781} & \multirow{2}{*}{.581} \\
\hline & FIT & 5.00 & 1.20 & & & & & \\
\hline
\end{tabular}

Legend. $p>0.05$ - not significant. $p<0.05$ - significant.

The table above shows no significant difference in the performance of the two integrative teaching groups on their integrated science process skills. Defining with a mean difference of 0.200 , hypothesizing of 0.033 , experimenting of 0.267 , and interpreting data of -0.100 .

This study implies that there is no significant difference between the pretest performances of the respondents that will undergo the two integrative teaching strategies. However, the results of the thematic teaching strategy group in terms of hypothesizing fall on the developing level, while the focusing inquiry teaching strategy group was on the beginning level. This means that before implementing the strategies, both groups have an outstanding level of experimenting skills and an approaching proficiency level in defining and interpreting data skills. Because the students already reached an outstanding level regarding their experimenting skills, the researcher revised the post-test order and altered some of the items that measure the experimenting ability of the learners (Fatmawati \& Rustaman, 2020). After the post-test, the data shows that the learners experimenting skills after the changes made in the test order and some alterations on the test items reveal that their experimenting ability is still at an outstanding level.

This research is related to the conducted study of Lati, Saksri, \& Promarak (2012), wherein the pretest utilized in their study shows no significant difference in terms of the 
respondent's integrated science process skill (Ortiz \& Aliazas, 2021). This could be because they had more chances to exercise the competences of associating and manipulating variables, defining operationally, formulating hypotheses, and experimenting, which teachers more emphasized during their middle and high school years (Desyandri et Al., 2019; Fitriana et Al., 2020). They had few opportunities to practice the skill of interpreting data and drawing conclusions.

However, because many instructors frequently skipped this time-consuming step, the learners' ability to interpret data and draw conclusions was underdeveloped (Beaumont \& Soyibo, 2010; Fitriana et Al., 2020). Concerning this study, the students lacked the opportunity to formulate their hypotheses. In explaining their thoughts and ideas, they were bound by using only two to three sentences in hypothesizing. The hypothesizing skills of the learners are not thoroughly measured because there are only a few items that the respondents answered (Saat, 2010; Panoy, 2017). That number is not sufficient enough to justify the learners' hypothesizing skills. Another reason is that in the question that the respondents need to answer, wherein if the Solar system's formation never happens in the first place, what do you think we have right now? The students had much to say and explain, but they were bounded by using few sentences to explain their answers.

\section{Table 6}

Test of difference between the pretest and post-test scores performance of Thematic Teaching group of respondents on integrated science process skills

\begin{tabular}{|c|c|c|c|c|c|c|c|c|c|}
\hline \multirow{3}{*}{ Skills } & \multirow{3}{*}{ Test } & \multirow{3}{*}{ Mean } & \multirow{3}{*}{$\mathrm{SD}$} & \multicolumn{4}{|c|}{ Paired Differences } & \multirow{3}{*}{$\mathrm{T}$} & \multirow{3}{*}{ Sig. } \\
\hline & & & & \multirow[t]{2}{*}{ Mean } & \multirow[t]{2}{*}{ SD } & \multicolumn{2}{|c|}{$\begin{array}{c}95 \% \mathrm{Cl} \text { of the } \\
\text { Diff. }\end{array}$} & & \\
\hline & & & & & & Lower & Upper & & \\
\hline \multirow[t]{2}{*}{ Defining } & Pretest & 5.70 & 1.60 & \multirow{2}{*}{1.90} & \multirow{2}{*}{1.63} & \multirow{2}{*}{1.293} & \multirow{2}{*}{2.507} & \multirow{2}{*}{6.399} & \multirow{2}{*}{0.000} \\
\hline & Posttest & 7.60 & 1.00 & & & & & & \\
\hline \multirow[t]{2}{*}{ Hypothesizing } & Pretest & 2.50 & 0.86 & \multirow{2}{*}{1.50} & \multirow{2}{*}{1.07} & \multirow{2}{*}{1.099} & \multirow{2}{*}{1.901} & \multirow{2}{*}{7.644} & \multirow{2}{*}{0.000} \\
\hline & Posttest & 4.00 & 0.69 & & & & & & \\
\hline \multirow[t]{2}{*}{ Experimenting } & Pretest & 8.03 & 3.22 & \multirow{2}{*}{3.97} & \multirow{2}{*}{2.98} & \multirow{2}{*}{2.855} & \multirow{2}{*}{5.078} & \multirow{2}{*}{7.299} & \multirow{2}{*}{0.000} \\
\hline & Posttest & 12.00 & 1.80 & & & & & & \\
\hline \multirow{2}{*}{$\begin{array}{l}\text { Interpreting } \\
\text { Data }\end{array}$} & Pretest & 4.90 & 1.42 & \multirow{2}{*}{2.93} & \multirow{2}{*}{1.70} & \multirow{2}{*}{2.298} & \multirow{2}{*}{3.568} & \multirow{2}{*}{9.448} & \multirow{2}{*}{0.000} \\
\hline & Posttest & 7.83 & 1.09 & & & & & & \\
\hline
\end{tabular}


The performance of the thematic teaching group and their integrated science process skills are shown in the table above. The mean reveals that the group performance in terms of defining skill is 1.90 , hypothesizing skill is 1.07 , experimenting skill is 2.98 , and 1.70 in their interpreting data skills. This study implies a significant difference in the pretest and post-test results of the students that undergo thematic teaching strategy. Their pretest scores reveal that this class has achieved outstanding experimenting skills and approaching proficiency in interpreting data and defining skills. However, the result of their hypothesizing skills indicates that they are in the beginning to developing level. Upon integrating the thematic teaching strategy, their post-test results show improved integrated science process skills. The thematic teaching group results in experimenting skills maintained to be an outstanding level (Saat, 2010; Fitriana et Al., 2020). On the other hand, the class's defining and interpreting skills improved because they could remember the terms and vocabulary in the post-test. Their hypothesizing skills are raised to developing to approaching proficiency.

About the above implication, Huong et Al. (2018) discuss the benefits of thematic teaching strategy when combined with designing homework and in-class activities using Socrates' questioning method and Bloom's taxonomy. The researcher's questioning method and integration became influential in developing their integrated science process skills (Desyandri et Al., 2019; Fitriana et Al., 2020). Students can better control their learning and understanding of their peers' points of view. When they express their opinions, they always provide reasonable evidence, rather than simply accepting the reasoning of others, demonstrating critical thinking skills.

Table 7 shows the performance of the focusing inquiry group concerning their integrated science process skills. It reveals that the group performance in terms of defining skills has a mean of 2.13, hypothesizing skills of 1.43 , experimenting skills of 4.07 , and interpreting data of 2.83. This study implies a significant difference between the pretest and post-test of the focusing inquiry strategy group. The pretest result of this group suggests their primary state upon the implementation of the strategy. Their integrated science process skills in terms of experimenting are outstanding, their defining and interpreting data are in approaching proficiency level, and their hypothesizing level falls to the beginning level. However, upon implementing the focusing inquiry teaching strategy, the respondents reveal 
significant improvement in their science process skills. Their experimenting skills remain on an outstanding level.

Table 7

Test of difference between the pretest and post-test scores performance of Focusing inquiry Teaching group of respondents on integrated science process skills

\begin{tabular}{|c|c|c|c|c|c|c|c|c|c|}
\hline \multirow{3}{*}{ Skills } & \multirow{3}{*}{ Test } & \multirow{3}{*}{ Mean } & \multirow{3}{*}{$\mathrm{SD}$} & \multicolumn{4}{|c|}{ Paired Differences } & \multirow{3}{*}{$\mathrm{t}$} & \multirow{3}{*}{ Sig. } \\
\hline & & & & \multirow{2}{*}{ Mean } & \multirow{2}{*}{ SD } & \multicolumn{2}{|c|}{$\begin{array}{c}95 \% \mathrm{Cl} \text { of the } \\
\text { Diff. }\end{array}$} & & \\
\hline & & & & & & Lower & Upper & & \\
\hline \multirow[t]{2}{*}{ Defining } & Pretest & 5.50 & 1.57 & \multirow{2}{*}{2.13} & \multirow{2}{*}{1.93} & \multirow{2}{*}{1.415} & \multirow{2}{*}{2.852} & \multirow{2}{*}{6.070} & \multirow{2}{*}{0.000} \\
\hline & Posttest & 7.63 & 1.16 & & & & & & \\
\hline \multirow[t]{2}{*}{ Hypothesizing } & Pretest & 2.47 & 0.97 & \multirow{2}{*}{1.43} & \multirow{2}{*}{1.22} & \multirow{2}{*}{0.977} & \multirow{2}{*}{1.890} & \multirow{2}{*}{6.420} & \multirow{2}{*}{0.000} \\
\hline & Posttest & 3.90 & 0.66 & & & & & & \\
\hline \multirow[t]{2}{*}{ Experimenting } & Pretest & 7.77 & 2.85 & \multirow{2}{*}{4.07} & \multirow{2}{*}{2.96} & \multirow{2}{*}{2.962} & \multirow{2}{*}{5.171} & \multirow{2}{*}{7.528} & \multirow{2}{*}{0.000} \\
\hline & Posttest & 11.83 & 1.56 & & & & & & \\
\hline \multirow{2}{*}{$\begin{array}{l}\text { Interpreting } \\
\text { Data }\end{array}$} & Pretest & 5.00 & 1.20 & \multirow{2}{*}{2.83} & \multirow{2}{*}{1.53} & \multirow{2}{*}{2.261} & \multirow{2}{*}{3.406} & \multirow{2}{*}{10.122} & \multirow{2}{*}{0.000} \\
\hline & Posttest & 7.83 & 0.99 & & & & & & \\
\hline
\end{tabular}

Legend. $p>0.05$ - not significant. $p<0.05$ - significant.

However, the integrated science process skills significantly improved in defining and interpreting data skills that raised proficiency (Utami \& Mustadi, 2019). The hypothesizing skills lift to developing to approaching proficiency. Following the preceding inference above, the findings in the study of Haug \& Ødegaard (2014) suggest that when students are required to apply key concepts in their talk throughout the focusing inquiry teaching strategy, their level of word knowledge progresses toward conceptual knowledge (Saat, 2010). When students discuss their ideas and findings after becoming acquainted with the fundamental concepts through the initial inquiry activities, they use them to further their conceptual understanding (Baharom et Al., 2020).

Theses associated with inquiry including asking questions, employing techniques to collect needed data, and thinking logically regarding the relationship of the context to real real-world scenarios. Using questions in the focusing inquiry process helps the students establish learning and further enhance their retention of what they are studying (Fatmawati \& Rustaman, 2020). According to the study conducted by National Research Council (2000), the standards on utilizing inquiry emphasize the learner's ability to develop thinking ways. This study's utilization helps improve students' capacity and build up their integrated science 
process skills (Utami \& Mustadi, 2019). Their knowledge and ideas are the considered contributing factor to their learnings. By integrating it into real-life scenarios, this knowledge and information are stored in the minds of every learner as long-term memory. In that way, the utilization of questions in the discussion of focusing inquiry strategy gives an advantage to the learners.

\section{Table 8}

Test of significance between the post-test score's performance of the two groups of respondents on integrated science process skills

\begin{tabular}{|c|c|c|c|c|c|c|c|c|}
\hline \multirow{3}{*}{ Skills } & \multirow{3}{*}{ Group } & \multirow{3}{*}{ Mean } & \multirow{3}{*}{$\mathrm{SD}$} & \multicolumn{5}{|c|}{ t-test for Equality of Means } \\
\hline & & & & \multirow[t]{2}{*}{$\mathrm{t}$} & \multirow[t]{2}{*}{ Sig. } & \multirow{2}{*}{$\begin{array}{l}\text { Mean } \\
\text { Diff. }\end{array}$} & \multicolumn{2}{|c|}{$\begin{array}{c}95 \% \mathrm{Cl} \text { of the } \\
\text { Diff. }\end{array}$} \\
\hline & & & & & & & Lower & Upper \\
\hline \multirow{2}{*}{ Defining } & TT & 7.60 & 1.00 & \multirow{2}{*}{-.119} & \multirow{2}{*}{.906} & \multirow{2}{*}{-.033} & \multirow{2}{*}{-.594} & \multirow{2}{*}{.527} \\
\hline & FIT & 7.63 & 1.16 & & & & & \\
\hline \multirow{2}{*}{ Hypothesizing } & $\mathrm{TT}$ & 4.00 & 0.69 & \multirow{2}{*}{.571} & \multirow{2}{*}{.570} & \multirow{2}{*}{.100} & \multirow{2}{*}{-.251} & \multirow{2}{*}{.451} \\
\hline & FIT & 3.90 & 0.66 & & & & & \\
\hline \multirow{2}{*}{ Experimenting } & $\mathrm{TT}$ & 12.00 & 1.80 & \multirow{2}{*}{.384} & \multirow{2}{*}{.703} & \multirow{2}{*}{.167} & \multirow{2}{*}{-.703} & \multirow{2}{*}{1.036} \\
\hline & FIT & 11.83 & 1.56 & & & & & \\
\hline \multirow{2}{*}{ Interpreting Data } & $\mathrm{TT}$ & 7.83 & 1.09 & \multirow{2}{*}{.000} & \multirow{2}{*}{1.000} & \multirow{2}{*}{.000} & \multirow{2}{*}{-.536} & \multirow{2}{*}{.536} \\
\hline & FIT & 7.83 & 0.99 & & & & & \\
\hline
\end{tabular}

Legend. $p>0.05-$ not significant. $p<0.05$ - significant.

The table above indicates the comparison between the post-test result of the two integrative teaching groups in their integrated science process skills. It reveals no significant difference in their integrated science process skills in terms of defining with a significant value of 0.906 and a hypothesizing value of 0.570 . experimenting value of 0.703 and interpreting data value of 1.000 .

This study implies no significant differences in the post-test of the two integrative groups after implementing the teaching strategies. The table shows the minimal interval between the integrated science process skills development of the students. It is then displayed in the means difference in terms of defining which is -0.033 , hypothesizing which is 0.100 , experimenting with a value of 0.703 , and interpreting data with 1.000 . at the end of the posttest, data revealed that after the implementation of the integrative teaching strategies, the learners from both groups integrated science process skills were strengthened and developed, their defining and interpreting data skills leveled up to proficient level, their hypothesizing 
skills raised to developing- approaching proficiency level and their experimenting skills at an outstanding level.

In light of the above implication, the study conducted by Michelazzo et Al. (2015), their findings indicated that the course raised overall knowledge levels. However, based on their specialty, the improvement was not equal for all individuals (Utami \& Mustadi, 2019). Those who had previously worked in a genetics setting showed no significant gain in their understanding (Saat, 2010; Panoy, 2017). This could be due to various circumstances, including the questions' extreme ease in terms of topic or language and the primary subject of the classes. The improvements made by the two integrative groups show similar results and achievements; therefore, there is no significant difference implied in the table above (Baharom et Al., 2020).

\section{Conclusion}

Prior to implementing the online integrative teaching strategy, students were randomly assigned to groups, and the results revealed no significant difference between the respondents' pretest scores in all components of integrated science process skills. After exposing the students to online integrative teaching strategies, the results showed that their performance scores improved (focusing inquiry and thematic teaching). Similarly, results revealed a significant difference between the respondents' pretest and post-test in all integrated science process skills components. There is no significant difference between the post-test of the respondents in all components of integrated science process skills (except for Interpreting Data: Sig:0.000). Thus, both integrative teaching strategies were deemed effective in improving the integrated science process skills of the students.

The pretest and post-test instruments are reviewed and improved to achieve a more concrete and appropriate congruence of the material's results. The findings suggest that further research be extended to obtain more reliable data and test the efficacy of the implemented teaching strategies. Lastly, it is advised to balance the number of items used to measure the study's designated variables. 


\section{References}

Aliazas, J.C., Panoy, J.D., Del Rosario, A.P. \& Madrideo, J.V. (2021). Critical Success Factors of the Flexible Learning Delivery as Organizational Innovation of One State University in the Philippines. International Journal of Educational Management and Development Studies, Volume 2, Issue 3, pp. 61 - 77. https://doi.org/10.53378/348736

Arinto, P. (2016). Issues and Challenges in Open and Distance e-Learning: Perspectives from the Philippines. International Review of Research in Open and Distributed Learning, 17(2), 162180. https://doi.org/10.19173/irrodl.v17i2.1913

Baharon, M., Atan, N., Rosli, M., Yusof, S., \& Abd Hamid, M., (2020). Integration of Science Learning Apps based on Inquiry-Based Science Education (IBSE) enhances Students Process Skills (SPS). International Association of Online Engineering.https://www.learntechlib.org/p/217832

Beaumont, Y.W, \& Soyibo, K. (2010). An Analysis of Highschool Students' Performance on Five Integrated Science Process Skills. Research in Science \& Technological Education, Volume 19, 2001- Issue 2. https://doi.org/10.1080/02635140120087687

Desyandri D., Muhammadi M., Mansurdin M., \& Fahmi R. (2019). Development of integrated thematic teaching material used discovery learning model in grade $\mathrm{V}$ elementary school. Jurnal Konseling dan Pendidikan is Nationally Accredited in SINTA 2 (Ministry of RTHE): 23/E/KPT/2019 No.5, https://doi.org/10.29210/129400

Dostál, J., \& Gregar, J. (2015). Inquiry-based instruction: Concept, essence, importance and contribution (p. 31). Olomouc: Univerzita Palackého v Olomouci.

Fatmawati, B., \& Rustaman, N.Y., (2020). The Study of Inquiry Ability in the Photosynthesis Concept. Indonesian Journal of Science Education Volume 9, No.4 2020. https://doi.org/10.15294/jpii.v9i4.23989

Fitriana, N., Wardani, K., Sunardi, S. \& Suharno, S. (2020). Context-Based Thematic Teaching Materials to Improve Elementary Students' Learning Achievements. Indonesian of Educational Journal. https://dx.doi.org/10.23887/jpi-undiksha.v9i2.22822

Fu, J. (2013). Complexity of ICT in education: A critical literature review and its implications. International Journal of Education and Development using ICT, 9(1), 112-125. Open Campus, The University of the West Indies, West Indies. https://www.learntechlib.org/p/111900/.

Hanfstingl, B., Benke, G., \& Zhang, Y. (2019). Comparing variation theory with Piaget's theory of cognitive development: more similarities than differences?. Educational Action Research, 27(4), 511-526.

Haug, B. S., \& Ødegaard, M. (2014). From Words to Concepts: Focusing on Word Knowledge When Teaching for Conceptual Understanding Within an Inquiry-Based Science Setting. Research in Science Education, 44(5), 777-800. doi:10.1007/s11165-014-9402-5

Huong, H. T. L., Huy, N. H. D., \& Ha, N. N. (2018). The Flipped classroom: Using thematic teaching to develop critical thinking for high school students. American Journal of Educational Research, 6(6), 828-835. 
Lati, W., Saksri, S \& Promarak, V. (2012). Enhancement of Learning Achievement and Integrated Science Process Skills using Science Inquiry Learning Activities of Chemical Reaction Rates. Procedia-Social and Behavioral Science, Volume 46, 2012 Pages 4471-4475. https://doi.org/10.1016/j.sbspro.2012.06.279

McCarty, C.B., (2005). Effects of Thematic-based, Hands-on Science Teaching Versus a Textbook Approach for Students with Disabilities. Journal of Research in Science Teaching/ Volume 42, Issue 3. https://doi.org/10.1002/tea.20057

Michelazzo, M. B., Pastorino, R., Mazzucco, W., \& Boccia, S. (2015). Distance learning training in genetics and genomics testing for Italian health professionals: results of a pre and post-test evaluation. Epidemiology, Biostatistics and Public Health, 12(3).

National Research Council. (2000). How people learn: Brain, mind, experience, and school: Expanded edition. National Academies Press.

Ortiz, A.M.L. \& Aliazas, J.V.C. (2021). Multimodal Representations Strategies in Teaching Science Towards Enhancing Scientific Inquiry Skills Among Grade 4. IOER International Multidisciplinary Research Journal. Volume 3 Issue 3, pp. 107-118. https://doi.org/10.5281/zenodo.5528447

Panoy, J. F. (2017). Perceived Relevance of Science and Scientific Literacy among Pre-Service Teachers. In Ascendens Asia Journal of Multidisciplinary Research Conference Proceedings (Vol. 1, No. 3).

Resor, C. W. (2017). Exploring Vacation and Etiquette Themes in Social Studies: Primary Source Inquiry for Middle and High School. Rowman \& Littlefield.

Richards, B. A., \& Frankland, P. W. (2017). The persistence and transience of memory. Neuron, 94(6), 1071-1084.

Saat, R.H., (2010). The Acquisition of Integrated Science Process Skills in Web-based Learning Environment. Research in Science \& Technological Education, Volume 22, 2004-Issue 1 Pages 23-40. https://doi.org/10.1080/0263514042000187520

Shahali, E.H.M, \& Halim, L. (2011). Developmental and Validation of a Test of Integrated Science Process Skills. Procedia-Social and Behavioral Sciences, Volume 9, 2010, Pages 142-146. https://doi.org/10.1016/j.sbspro.2010.12.127

Utami, H.H, \& Mustadi, A., (2019), The Students Process Skills in Integrative Thematic Learning with Scientific Approach. Advances in Social Science, Education and Humanities Research, Volume 326. https://doi.org/10.2991/iccie-18.2019.40

Vanoostveen, R., Desjardins, F., \& Bullock, S. (2019). Professional development learning environments (PDLEs) embedded in a collaborative online learning environment (COLE): Moving towards a new conception of online professional learning. Education and information technologies, 24(2), 1863-1900. 